\title{
Differential regulation of angiogenic cellular processes and claudin- 5 by histamine and VEGF via PI3K-signaling, transcription factor SNAI2 and interleukin-8
}

Citation for published version (APA):

Laakkonen, J. P., Lappalainen, J. P., Theelen, T. L., Toivanen, P. I., Nieminen, T., Jauhiainen, S., Kaikkonen, M. U., Sluimer, J. C., \& Yla-Herttuala, S. (2017). Differential regulation of angiogenic cellular processes and claudin- 5 by histamine and VEGF via PI3K-signaling, transcription factor SNAI2 and interleukin-8. Angiogenesis, 20(1), 109-124. https://doi.org/10.1007/s10456-016-9532-7

Document status and date:

Published: 01/02/2017

DOI:

10.1007/s10456-016-9532-7

Document Version:

Publisher's PDF, also known as Version of record

Document license:

Taverne

Please check the document version of this publication:

- A submitted manuscript is the version of the article upon submission and before peer-review. There can be important differences between the submitted version and the official published version of record. People interested in the research are advised to contact the author for the final version of the publication, or visit the DOI to the publisher's website.

- The final author version and the galley proof are versions of the publication after peer review.

- The final published version features the final layout of the paper including the volume, issue and page numbers.

Link to publication

\footnotetext{
General rights rights.

- You may freely distribute the URL identifying the publication in the public portal. please follow below link for the End User Agreement:

www.umlib.nl/taverne-license

Take down policy

If you believe that this document breaches copyright please contact us at:

repository@maastrichtuniversity.nl

providing details and we will investigate your claim.
}

Copyright and moral rights for the publications made accessible in the public portal are retained by the authors and/or other copyright owners and it is a condition of accessing publications that users recognise and abide by the legal requirements associated with these

- Users may download and print one copy of any publication from the public portal for the purpose of private study or research.

- You may not further distribute the material or use it for any profit-making activity or commercial gain

If the publication is distributed under the terms of Article 25fa of the Dutch Copyright Act, indicated by the "Taverne" license above, 


\title{
Differential regulation of angiogenic cellular processes and claudin-5 by histamine and VEGF via PI3K-signaling, transcription factor SNAI2 and interleukin-8
}

\author{
Johanna P. Laakkonen ${ }^{1} \cdot$ Jari P. Lappalainen ${ }^{1} \cdot$ Thomas L. Theelen $^{2}$. \\ Pyry I. Toivanen $^{1} \cdot$ Tiina Nieminen $^{1} \cdot$ Suvi Jauhiainen ${ }^{1} \cdot$ Minna U. Kaikkonen ${ }^{1}$ • \\ Judith C. Sluimer $^{2} \cdot$ Seppo Ylä-Herttuala ${ }^{1}$
}

Received: 30 June 2016/Accepted: 7 November 2016/Published online: 21 November 2016

(C) Springer Science+Business Media Dordrecht 2016

\begin{abstract}
Aims Histamine and vascular endothelial growth factor A (VEGF) are central regulators in vascular pathologies. Their gene regulation leading to vascular remodeling has remained obscure. In this study, EC regulation mechanisms of histamine and VEGF were compared by RNA sequencing of primary endothelial cells (ECs), functional in vitro assays and in vivo permeability mice model.

Methods and results By RNA sequencing, similar transcriptional alterations of genes involved in activation of primary ECs, cell proliferation and adhesion were observed between histamine and VEGF. Seventy-six commonly regulated genes were found, representing $\sim 53 \%$ of all VEGF-regulated transcripts and $\sim 26 \%$ of all histamineregulated transcripts. Both factors regulated tight junction formation and expression of pro-angiogenic transcription factors (TFs) affecting EC survival, migration and tube formation. Novel claudin-5 upstream regulatory genes were identified. VEGF was demonstrated to regulate expression of SNAI2, whereas pro-angiogenic TFs NR4A1, MYCN and RCAN1 were regulated by both histamine and
\end{abstract}

Johanna P. Laakkonen and Jari P. Lappalainen have contributed equally to this work.

Electronic supplementary material The online version of this article (doi:10.1007/s10456-016-9532-7) contains supplementary material, which is available to authorized users.

Johanna P. Laakkonen

johanna.p.laakkonen@uef.fi

1 Department of Biotechnology and Molecular Medicine, A.I. Virtanen Institute for Molecular Sciences, University of Eastern Finland, Kuopio, Finland

2 Department of Pathology, CARIM, Maastricht University Medical Center, Maastricht, The Netherlands
VEGF. Claudin-5 was shown to be regulated VEGFR2/ PI3K-Akt dependently by VEGF and PI3K-Akt independently by histamine. Interleukin-8 was shown to downregulate claudin-5 by histamine. Additionally, SNAI2, NR4A1 and MYCN were shown to mediate EC survival, migration and tube formation and to regulate expression of claudin-5. Further systemic delivery of VEGF and histamine was shown to induce a fast vascular hyperpermeability response in intact vasculature of $\mathrm{C} 57 / \mathrm{B} 16$ mice followed by regulation of NR4A1 and MYCN.

Conclusions Our study identifies novel claudin-5 upstream regulatory genes of histamine and VEGF that induce cellular angiogenic processes. Our results increase knowledge of angiogenic EC phenotype and provide novel treatment targets for vascular pathologies.

Keywords Vascular endothelial growth factors .

Histamine - Endothelial cell proliferation - Angiogenesis · Vascular permeability

\section{Introduction}

Vascular endothelial growth factor and inflammatory mediator histamine are well-known edematogenic factors involved in many vascular diseases. Increased levels of histamine have been reported in response to trauma, allergy, burns and infectious diseases [1], whereas increased VEGF levels are linked to cancer, vascular anomalies and asthma [2-4]. Both histamine and VEGF cause vasodilatation, vascular hyperpermeability and local attraction of inflammatory cells. They are released from degranulated mast cells, often found near inflammation and angiogenic sites [5]. Besides their role in hyperpermeability, VEGF but also histamine is suggested to induce EC 
proliferation and angiogenesis [6, 7]. Histamine-induced angiogenesis has been observed in primary ECs [6], rabbit cornea [8] and after subcutaneous implantation of histamine pellets in mice [6]. Additionally, defective angiogenesis has been observed in histidine decarboxylase knockout mouse that catalyzes histamine synthesis [9] and after treatment with histamine receptor antagonist [7]. In spite of previous work on early events of histamine and VEGF signaling, and the use of VEGFs in pro-angiogenic therapy, gene regulation by which these factors induce pathological angiogenesis is largely unknown.

Histamine has four receptors (HR1-4) that belong to G-protein-coupled receptor (GPCR) family, from which HR1 and HR2 are expressed in ECs. VEGFs instead bind to VEGF receptors 1-3 (VEGFR), while neuropilins 1-2 (NRP) and heparan sulfate proteoglycans (HSPGs) act as co-receptors. Several VEGF family members (VEGF-A-F, placental growth factor) and their isoforms have been identified [2]. VEGFR2 has been suggested to be the main receptor responsible for VEGF-induced angiogenesis with all VEGF family members. In contrast, histamine has been suggested to induce either expression of (1) VEGF [9] or (2) NR4A1 (nuclear receptor subfamily 4 group A member 1) transcription factor [6] that further mediate vascular permeability and angiogenesis. So far no genome-wide studies exist comparing these two pro-angiogenic and edematogenic factors that would provide mechanistic insight on their function in ECs.

The goal of our study was to define the mechanisms leading to angiogenic phenotype of ECs by histamine and VEGF and compare whether there are similarities in gene expression profiles between these factors that could explain their pro-angiogenic and edematogenic effects. To study this, we used novel deep-sequencing technology (RNA sequencing, RNA-seq) that covers information of all mRNA transcripts of the cell. In comparison with microarray technology, RNA-seq does not require transcript or species-specific probes, is not limited to known transcripts and is more sensitive to detect genes having low expression levels. Besides RNA-seq, we used 2-photon microscopy enabling imaging of $3 \mathrm{D}$ organization of the vasculature and functional assays detecting EC survival, permeability, migration and tube formation to validate the data. Our study demonstrates novel common molecular players involved in angiogenic processes affecting, e.g., EC activation, adhesion and proliferation by histamine and VEGF. We show that $\sim 53 \%$ of all VEGF-regulated transcripts and $\sim 26 \%$ of all histamine-regulated transcripts are commonly regulated, involving genes regulating calcium signaling, tight junction (TJ) formation and actin re-organization. Downregulation of the major TJ gene claudin-5 and pro-angiogenic EC phenotype was shown to be mediated by PI3K signaling and pro-angiogenic transcription factors SNAI2 (snail family zinc finger 2), MYCN (N-myc proto-oncogene protein) and NR4A1. No increase in the expression of VEGFs/VEGFRs by histamine was detected that could explain the commonly induced genes and functional effects in ECs. Consistently, after inducing vascular hyperpermeability in C57/B16 mice by histamine or VEGF, changes in expression of claudin-5 upstream regulators NR4A1 and MYCN were observed. Conclusively, our data demonstrate for the first time that both histamine and VEGF induce expression of multiple common genes that regulate EC activation, adhesion and act as upstream regulators of claudin-5. Understanding the mechanisms of angiogenic processes and their underlying gene regulation is crucial for the development of novel ways to reduce edema in pathological conditions and to develop pro- and anti-angiogenic therapies.

\section{Methods}

Detailed methods section is available in the Data Supplement.

\section{Experimental animals}

All experiments were performed with 8- to 12-week-old male C57/B16 mice (Harlan Laboratories). For vascular permeability experiments, mice received an intravenous injection of green fluorescent microspheres $(200 \mathrm{~nm})$ followed by injection with $0.25 \mu \mathrm{g} / \mathrm{g}$ of human recombinant VEGFs or $12.5 \mu \mathrm{g} / \mathrm{g}(4 \mathrm{~h})$ and $25 \mu \mathrm{g} / \mathrm{g}(10 \mathrm{~min})$ of histamine under isoflurane anesthesia. Saline was used as control. Mice were killed $10 \mathrm{~min}, 30 \mathrm{~min}$ or $4 \mathrm{~h}$ after injections and perfused with PBS ( $n=4-5$ mice/group). Tissues were harvested and snap-frozen for qRT-PCR and western blot (WB). For imaging, tissues were fixed in $4 \%$ PFA-PBS, sliced to 1-mm whole immune mount sections and immunostained with rat anti-mouse CD31 and goat anti-rat Alexa 594 antibodies. Animal experiments were approved by National Experimental Animal Board of Finland and carried out in accordance with guidelines from Directive 2010/63/EU of the European Parliament on the protection of animals used for scientific purposes.

\section{qRT-PCR}

Confluent cultures of primary human umbilical vein ECs (HUVECs, 3-4 donors) or human aortic ECs (HAECs, 3 donors) were starved for $16 \mathrm{~h}$ with medium supplemented with $0.5 \%$ FBS. In all experiments, ECs were stimulated with VEGFs or histamine for 4 or $7 \mathrm{~h}$. Three independent experiments were performed, containing each of three replicates. Tissue samples were homogenized with 
Precellys 24 tissue homogenizer. Total RNA was extracted and reverse transcribed into cDNA using random hexamers and RevertAid RT. Quantitative measurements of mRNAs were performed with StepOnePlus Real-Time PCR System.

\section{RNA-seq}

RNA was extracted from histamine- or VEGF-stimulated HUVECs after $7 \mathrm{~h}$ of exposure. Two independent experiments were performed (4 donors, using separate donors in independent experiments). After enrichment and fragmentation of RNA, poly(A) tailing and cDNA synthesis were performed [10]. For reverse transcription, an oligo allowing custom barcoding during final amplification was used. Libraries were amplified and sequenced on HiSeq 2000 according to the manufacturer's instructions (GeneCore, EMBL). RNA-seq was mapped using TopHat (v2.0.7). Each sequencing experiment was normalized to a total of $10^{7}$ uniquely mapped tags and visualized by preparing custom tracks for the UCSC genome browser. Following thresholds were used: $P$ value $<0.05$, RPKM $>0.5$, fold change $>1.6$. RNA-seq data were further validated on selected genes by qRT-PCR by two independent experiments, containing each of three replicates. The RNA-seq data are available in GEO under the accession number GSE58663.

\section{Results}

\section{Common gene expression profile regulates VEGF- and histamine-induced changes in EC function}

To characterize the transcriptional alterations of genes inducing angiogenic phenotype of ECs, RNA-seq was performed from HUVECs after $7 \mathrm{~h}$ of exposure to histamine or VEGF. In our omics approach, genes known to regulate EC and ECM adhesion, proliferation, ion flux and immune response were compared between the factors. Despite different receptor binding profile of VEGF and histamine to VEGFR2 and H1R, respectively, 76 genes were shown to be commonly regulated between VEGF- $\mathrm{A}_{165}$ and histamine (Fig. 1a, b; Table 1; Suppl. Table 1), representing 53\% of all VEGF-regulated transcripts and $\sim 26 \%$ of all histamineregulated transcripts. Accordingly, $47 \%$ of all RNA transcripts $(n=67)$ were solely regulated by VEGF and $\sim 74 \%$ by histamine ( $n=215$; Table 2$)$. Within the commonly induced genes, a similar regulation pattern was observed, having a strong positive correlation $\left(r^{2}=0.8\right.$; Fig. 1c). To further identify these gene groups, gene ontology (GO) analysis was performed. The analysis demonstrated that the genes were involved particularly in cell differentiation, development and adhesion (Fig. 1d, f-g; Table 3). Both factors regulated GPCR signaling involved in calcium influx/release, cytokine-cytokine interactions as well as PI3K-Akt pathway involved, e.g., in cell proliferation (Fig. 1e; Table 4; Suppl. Table 2). Histamine also regulated genes involved in inflammation, e.g., genes regulating diapedesis, type I interferon pathway, as well as chemokine and Toll-like receptor signaling pathways. Additionally, activation of genes involved in complement and coagulation cascades was detected. To exclude that histamine did not induce VEGF expression and thereby a similar expression pattern of commonly regulated genes, qRT-PCR and WB analyses were performed from histamine-stimulated cells from 4- to 7-h time points for qRT-PCR and $7 \mathrm{~h}$ for WB. No significant change in VEGF expression was detected either in qRT-PCR experiments, RNA-seq data or in WB (Suppl. Table 1; Suppl. Fig. 1A). Additionally, no changes in expression levels of VEGFRs were detected by RNAseq. These data therefore suggest that histamine and VEGF induce pro-angiogenic phenotype of ECs via similar mechanisms despite their different receptor binding profile.

\section{VEGF-mediated vascular hyperpermeability is time dependent and varies in different vascular beds}

Vascular permeability is one of the first indicators of altered EC adhesion in angiogenesis. In our study, remodeling of EC adhesion was followed after both short(10-30 $\mathrm{min})$ and long-term exposures to histamine or VEGFR2-binding VEGFs $(4,7 \mathrm{~h})$ in primary human ECs and in intact vasculature of $\mathrm{C} 57 / \mathrm{B} 16$ mice, together with functional in vitro assays and immunofluorescence (IF) staining of the cell junctional proteins. First, vascular hyperpermeability response induced by histamine and VEGFs was compared in the vasculature of C57/B16 mice. Extravasation of fluorescent microspheres from the vessels was used as an indicator of vascular permeability. After 10 or $30 \mathrm{~min}$ of injection of histamine or VEGF and fluorescent microspheres (i.v.), mice were killed, perfused and the vasculature was immunostained by CD31. Due to its wellknown and relative simple organization of $3 \mathrm{D}$ vasculature, trachea was used as a target tissue to detect the vascular leakage. Additionally, biodistribution, i.e., vascular leakage of the fluorescent particles, was detected from liver, spleen, kidney, heart and the lungs. After $10 \mathrm{~min}$ of exposure, vascular leakage of 200-nm fluorescent microspheres was visible by laser scanning microscopy in $\sim 20$ $\mu \mathrm{m}$-sized vessels of trachea with HR1/2-binding histamine, VEGFR1/2-binding VEGF- $A_{165}$ and VEGFR2-binding VEGF-F, indicating a fast hyperpermeability response of the vessels (Fig. 2a) due to gap formations between ECs. No vascular leakage was detected after injection of VEGFR2/3-binding VEGF-D $\mathrm{D}_{\Delta \mathrm{N} \Delta \mathrm{C}}$, having lower affinity 


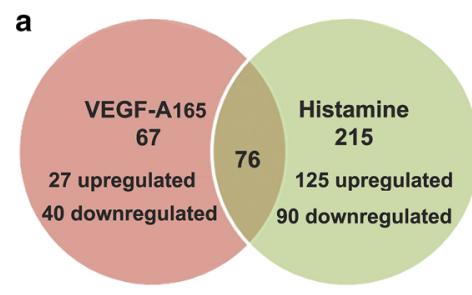

c

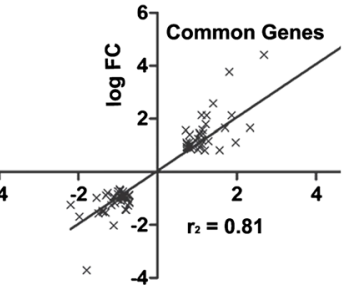

\begin{tabular}{lll}
\multicolumn{4}{l}{ Gene Ontology - Histamine induced Genes } \\
\hline Term & Count & p-value \\
\hline cell communication & 104 & $9.9 \mathrm{E}-09$ \\
type I interferon pathway & 9 & $4.3 \mathrm{E}-07$ \\
response to stress & 72 & $3.5 \mathrm{E}-06$ \\
response to wounding & 32 & $2.7 \mathrm{E}-05$ \\
tissue development & 37 & $4.2 \mathrm{E}-05$ \\
cell differentiation & 60 & $3.2 \mathrm{E}-04$ \\
\hline
\end{tabular}

Fig. 1 Histamine and VEGF regulate pro-angiogenic gene expression similarly in ECs. a RNA-seq was performed from HUVECs treated with VEGF-A $165(100 \mathrm{ng} / \mathrm{ml})$ or histamine $(20 \mu \mathrm{M})$ for $7 \mathrm{~h}$. Venn diagram showing all significantly regulated genes in treated ECs, revealing 76 commonly regulated genes. b Heat map showing all genes in non-treated ECs (Notx) and in VEGF- or histaminetreated ECs. Normalized gene expression values are shown (red,

d
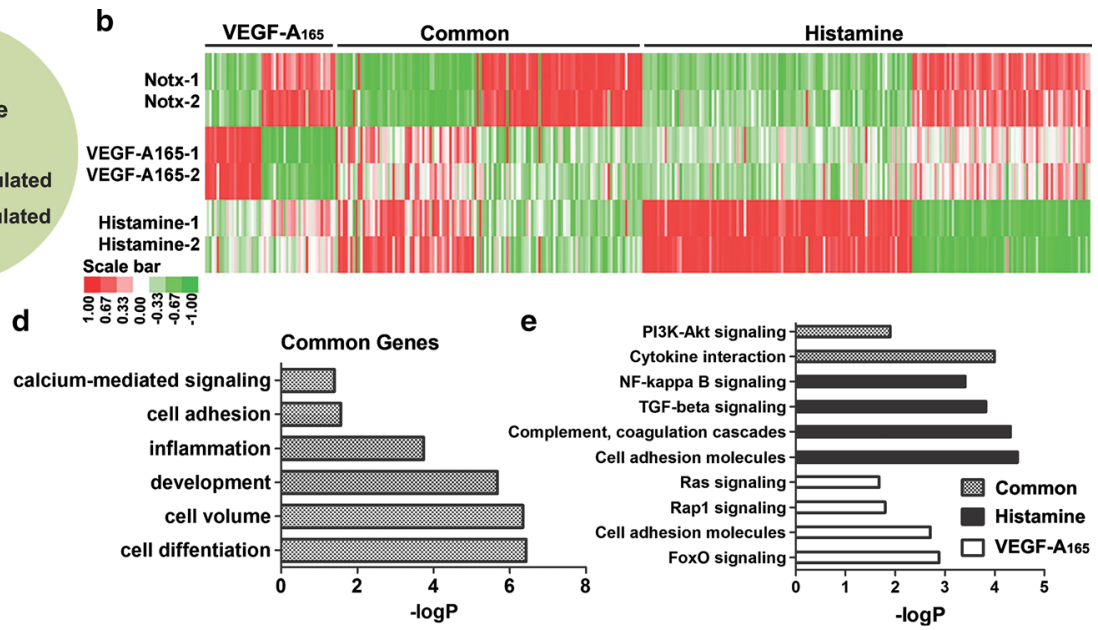

9 Gene Ontology - VEGF Induced Genes

\begin{tabular}{lll}
\hline Germ & Count & $p$-value \\
\hline regulation of cell differentiation & 12 & $1.6 \mathrm{E}-03$ \\
system, organ development & 22 & $8.0 \mathrm{E}-03$ \\
response to stress & 19 & $1.5 \mathrm{E}-02$ \\
response to wounding & 9 & $1.5 \mathrm{E}-02$ \\
cell communication & 25 & $1.9 \mathrm{E}-02$ \\
\hline
\end{tabular}

upregulated; green, downregulated genes). c-d Scatter plot (c) and gene ontology analysis (d) of commonly regulated genes. e KEGG pathway analysis of commonly regulated genes (gray), histamine (black) and VEGF (white) regulated genes. f-g Gene ontology analyses of histamine- (f) and VEGF-regulated genes (g). In all data, two independent experiments from separate donors were performed $(n=4$ donors $)$
Table 1 Top 10 commonly upregulated genes after VEGF or histamine stimulation in HUVECs at 7-h time point

\begin{tabular}{|c|c|c|c|c|}
\hline Gene symbol & LogFC (VEGF) & FDR (VEGF) & LogFC (histamine) & FDR (histamine) \\
\hline \multicolumn{5}{|c|}{ Commonly regulated genes } \\
\hline STC1 & 5.03 & $2.11 \mathrm{E}-129$ & 2.11 & $2.74 \mathrm{E}-09$ \\
\hline $\mathrm{PMCH}$ & 2.69 & $3.33 \mathrm{E}-05$ & 4.41 & $8.77 \mathrm{E}-31$ \\
\hline $\mathrm{NR} 4 \mathrm{~A} 1^{\mathrm{a}}$ & 2.34 & $5.15 \mathrm{E}-18$ & 1.66 & $1.20 \mathrm{E}-07$ \\
\hline $\mathrm{A} 2 \mathrm{M}$ & 1.98 & $4.15 \mathrm{E}-13$ & 1.11 & $3.04 \mathrm{E}-03$ \\
\hline CCL20 & 1.81 & $3.99 \mathrm{E}-02$ & 3.77 & $2.18 \mathrm{E}-16$ \\
\hline DNALI1 & 1.70 & $1.81 \mathrm{E}-12$ & 1.67 & $1.93 \mathrm{E}-13$ \\
\hline $\mathrm{LBH}$ & 1.40 & $4.04 \mathrm{E}-12$ & 2.58 & $1.25 \mathrm{E}-55$ \\
\hline RCAN1 $^{\mathrm{a}}$ & 1.23 & $9.17 \mathrm{E}-26$ & 2.13 & $5.14 \mathrm{E}-77$ \\
\hline KITLG & 1.21 & $2.11 \mathrm{E}-18$ & 1.80 & $3.80 \mathrm{E}-27$ \\
\hline HDAC9 & 1.14 & $1.16 \mathrm{E}-03$ & 1.59 & $3.00 \mathrm{E}-08$ \\
\hline
\end{tabular}

STC1 stanniocalcin 1, PMCH pro-melanin-concentrating hormone, NR4A1 nuclear receptor subfamily 4, group A, member 1, A2M alpha-2-macroglobulin, CCL2O chemokine (C-C motif) ligand 20, DNALII dynein, axonemal, light intermediate chain 1, $L B H$ limb bud and heart development, RCAN1 regulator of calcineurin 1, HDAC9 histone deacetylase 9

${ }^{a}$ Commonly upregulated transcription factors binding to VEGFR2 [11], or saline-injected control mice. Quantification of microspheres from CD31-labeled vessels showed a 49-fold increase of vascular permeability in histamine and a eightfold increase in VEGF-F-treated mice (Fig. 2b, c), whereas no statistically significant effect was detected with VEGF-A $\mathrm{A}_{165}$ after $10 \mathrm{~min}$ of exposure (1.6-fold,
$P>0.05$ ). Instead, $30 \mathrm{~min}$ after injection a 17-fold increase in vascular permeability was detected with VEGF$\mathrm{A}_{165}$ and a 12-fold with VEGF-F (Fig. 2h), demonstrating that vascular hyperpermeability induced by VEGFs increased over time. No differences between treatments were detected in liver (10 or $30 \mathrm{~min}$; Fig. 2d), whereas 
Table 2 Top 10 VEGF- or histamine-specific genes upregulated in HUVECs at 7-h time point

\begin{tabular}{lll}
\hline Gene symbol & Gene name & FDR \\
\hline VEGF specific $^{\text {MEF2C }}{ }^{\mathrm{a}}$ & & \\
Myocyte enhancer factor 2C & $3.66 \mathrm{E}-29$ \\
DNAJB9 & DnaJ (Hsp40) homolog, subfamily B, member 9 & $1.34 \mathrm{E}-17$ \\
ST8SIA4 & ST8 alpha-N-acetyl-neuraminide alpha-2,8-sialyltransferase 4 & $7.69 \mathrm{E}-10$ \\
SULT1C4 & Sulfotransferase family, cytosolic, 1C, member 4 & $9.99 \mathrm{E}-10$ \\
ARHGAP20 & Rho GTPase-activating protein 20 & $1.96 \mathrm{E}-06$ \\
PDGFD & Platelet-derived growth factor D & $2.46 \mathrm{E}-06$ \\
PRDM1 & PR domain containing 1, with ZNF domain & $2.41 \mathrm{E}-05$ \\
EGR3 & Early growth response 3 & $5.08 \mathrm{E}-05$ \\
MYCN & V-Myc myelocytomatosis viral-related oncogene & $9.45 \mathrm{E}-04$ \\
SNAI2 & & $4.72 \mathrm{E}-02$ \\
Histamine specific & Snail homolog 2 & \\
SERPINB2 & Serpin peptidase inhibitor & $1.36 \mathrm{E}-125$ \\
FST & Follistatin & $1.70 \mathrm{E}-102$ \\
AKAP12 & A kinase (PRKA) anchor protein 12 & $5.60 \mathrm{E}-81$ \\
RELN & Reelin & $8.05 \mathrm{E}-69$ \\
PLAU & Plasminogen activator, urokinase & $1.25 \mathrm{E}-55$ \\
PLAT & Plasminogen activator, tissue & $1.68 \mathrm{E}-50$ \\
SEMA3A & Semaphorin 3A & $1.01 \mathrm{E}-46$ \\
MALL & Mal, T cell differentiation protein like \\
PEG10 & Paternally expressed 10 & $2.62 \mathrm{E}-39$ \\
MYADM & Myeloid-associated differentiation marker & $1.80 \mathrm{E}-32$ \\
\hline
\end{tabular}

${ }^{a}$ Upregulated transcription factors and transcription enhancer factors

Table 3 GO analysis of commonly regulated genes in HUVEC cells after $7 \mathrm{~h}$ of VEGF and histamine exposure

\begin{tabular}{|c|c|c|}
\hline GO & Term & Genes \\
\hline $\begin{array}{l}\text { GO:0045595 } \\
\text { GO:0050793 }\end{array}$ & $\begin{array}{l}\text { Regulation of cell } \\
\text { differentiation } \\
\text { and developmental process }\end{array}$ & $\begin{array}{l}\text { PTHLH, DLL1, FITM2, AQP1, MAFB, KITLG, RCAN1, SMOC1, HGF, GDPD5, SEMA6A, } \\
\text { ABCA1, HDAC9, GDF7 }\end{array}$ \\
\hline $\begin{array}{l}\text { GO:0048731 } \\
\text { GO:0009888 } \\
\text { GO:0048513 }\end{array}$ & $\begin{array}{l}\text { Organ, system and tissue } \\
\text { development }\end{array}$ & $\begin{array}{l}\text { CLDN5, PTHLH, NR4A1, AQP1, MYO7A, MAFB, KALRN, TNFSF10, SMOC1, RCAN1, } \\
\text { GDPD5, SEMA6A, DOK5, HDAC9, CYP1A1, DLL1, KITLG, HGF, SLC12A2, STC1, } \\
\text { NLGN4Y, GDF7 }\end{array}$ \\
\hline GO:0007154 & Cell communication & $\begin{array}{l}\text { PTHLH, CCL20, NR4A1, PMCH, A2M, KALRN, TNFSF10, } \\
\text { DNAJB11, SMOC1, RCAN1, RASD1, SEMA6A, DOK5, HDAC9, DLL1, BCL2A1, KITLG, } \\
\text { ARHGAP28, OPRL1, HGF, ANXA9, SLC12A2, ABCA1, STC1, GDF7 }\end{array}$ \\
\hline GO:0071320 & Cellular response to cAMP & STC1, AQP1 \\
\hline GO:0002673 & $\begin{array}{l}\text { Regulation of acute } \\
\text { inflammatory response }\end{array}$ & ALOX5AP, A2M \\
\hline GO:0007186 & $\begin{array}{l}\text { G-protein-coupled receptor } \\
\text { signaling pathway }\end{array}$ & RASD1, OPRL1, PTHLH, SLC12A2, PMCH, ABCA1 \\
\hline
\end{tabular}

VEGF-F caused a fivefold less vascular leakage in spleen at 10-min time point compared to other VEGFs or histamine (Fig. 2e). Additionally, no leakage of microspheres was detected in kidneys or heart. To further distinguish the role of VEGF co-receptors NRP1/2 and HSPGs in VEGFinduced vascular hyperpermeability, experiments were performed with VEGF isoform $\mathrm{A}_{121}$ which has reduced binding affinity to NRP receptors and HSPGs compared to VEGF-A $A_{165}$ or VEGF-F and increased solubility [11]. At 30-min time point, VEGF-A 121 did not induce statistically significant vascular permeability in trachea (Fig. 2f, h), whereas in the lungs and spleen, a twofold increase in vascular leakage of the fluorescent particles was detected (Fig. 2i, j). Therefore, VEGF binding to NRP receptors or 
Table 4 Gene regulation of major signaling pathways by VEGF and histamine in HUVEC cells after $7 \mathrm{~h}$ of exposure

\begin{tabular}{|c|c|c|}
\hline ID term (pathway) & Term & Genes \\
\hline \multirow[t]{4}{*}{ hsa04060 } & \multicolumn{2}{|c|}{ Cytokine-cytokine receptor interaction } \\
\hline & VEGF-A & KITLG, TNFSF10, HGF, CCL20 \\
\hline & & CCL7, BMP2, TNFSF13, CXCL11, CCL20", \\
\hline & Histamine & IL8, TNFSF10 ${ }^{\mathrm{a}}, \mathrm{KITLG}^{\mathrm{a}}, \mathrm{HGF}^{\mathrm{a}}$, GDF5 \\
\hline \multirow[t]{3}{*}{ hsa04151 } & \multicolumn{2}{|c|}{ PI3K-Akt signaling pathway } \\
\hline & VEGF-A & PDGFD, KITLG, HGF, BCL2L11, NR4A1 \\
\hline & Histamine & $\mathrm{KITLG}^{\mathrm{a}}, \mathrm{HGF}^{\mathrm{a}}, \mathrm{RELN}, \mathrm{ITGB} 8, \mathrm{NR}^{4} 1^{\mathrm{a}}$ \\
\hline \multirow[t]{2}{*}{ hsa04610 } & \multicolumn{2}{|c|}{ Complement and coagulation cascades } \\
\hline & Histamine & PLAU, PLAT, SERPIND1, A2M ${ }^{\mathrm{a}}$ \\
\hline \multirow[t]{2}{*}{ hsa04068 } & \multicolumn{2}{|c|}{ FoxO signaling pathway } \\
\hline & VEGF-A & TNFSF10 ${ }^{\mathrm{a}}$, FBXO32 ${ }^{\mathrm{a}}, \mathrm{BCL} 2 \mathrm{~L} 11$ \\
\hline \multirow[t]{3}{*}{ hsa04015, hsa04014 } & \multicolumn{2}{|c|}{ Rap1 and Ras signaling pathways } \\
\hline & VEGF-A & PDGFD, KITLG, HGF \\
\hline & Histamine & $\mathrm{KITLG}^{\mathrm{a}}, \mathrm{HGF}^{\mathrm{a}}, \mathrm{MAP} 2 \mathrm{~K} 6$ \\
\hline \multirow[t]{2}{*}{ hsa04350 } & \multicolumn{2}{|c|}{ TGF-beta signaling pathway } \\
\hline & Histamine & BMP2, FST, GDF5, GDF7 ${ }^{\mathrm{a}}$ \\
\hline \multirow[t]{2}{*}{ hsa04064 } & \multicolumn{2}{|c|}{ NF-kappaB signaling pathway } \\
\hline & Histamine & BIRC3, PLAU, BCL2A1 ${ }^{\mathrm{a}}$, IL8 \\
\hline \multirow[t]{2}{*}{ hsa04668 } & \multicolumn{2}{|c|}{ TNF signaling pathway } \\
\hline & Histamine & BIRC3, CCL20 ${ }^{\mathrm{a}}$, RPS6KA5, MAP2K6 \\
\hline \multirow[t]{2}{*}{ hsa04390 } & \multicolumn{2}{|c|}{ Hippo signaling pathway } \\
\hline & Histamine & BMP2, GDF5, TEAD2, GDF7 ${ }^{\mathrm{a}}$ \\
\hline
\end{tabular}

${ }^{a}$ Common genes with VEGF and histamine
HSPGs seems to further affect the permeability profile induced by VEGFs. In accordance with in vivo results, permeability assay in HUVECs showed that VEGF-A 165 significantly induced EC permeability of a fluorescent marker after $15 \mathrm{~min}$ of exposure, whereas VEGF-A $\mathrm{A}_{121}$ or VEGF-D $_{\triangle \mathrm{N} \Delta \mathrm{C}}$ had no effect (Suppl. Fig. 1D). Redistribution of VE-cadherin, a major adherens junction (AJ) protein and changes in F-actin organization were also seen 30 min after exposure to VEGF-A ${ }_{121}$, VEGF-A V $_{165}$, VEGF$\mathrm{F}$ and histamine, whereas VEGF- $\mathrm{D}_{\Delta \mathrm{N} \Delta \mathrm{C}}$ did not induce any major changes (Suppl. Fig. 1B). Taken together, these data confirmed that both histamine and all high affinity binding VEGFR2 ligands regulate EC-EC adhesion and vascular permeability by modulating VE-cadherin and F-actin organization. Previously, no corresponding studies have been performed that would have compared these VEGF family members in intact vasculature of mice after systemic delivery. Additionally, co-receptor binding to NRPs/ HSPGs was shown to be an important factor influencing VEGF-mediated vascular permeability response. Due to the heterogeneity of the endothelium in different organs, vascular permeability response was shown to be dependent on the detected vascular bed, emphasizing the importance to study vascular permeability of all edematogenic factors in various target tissues.

\section{Expression of a major tight junction protein claudin-5 is downregulated by histamine and VEGFR2-binding VEGFs after long-term stimulation}

Previously, several studies have shown that short-term exposure to histamine or VEGF- $\mathrm{A}_{165}$ induces phosphorylation cascades that affect formation of $\mathrm{AJs}$ [12, 13]. However, changes in EC gene expression leading to pathological angiogenesis are not well known, although both histamine and VEGF have been connected to various pathological states. To gain more detailed understanding of the long-term regulation of EC-EC adhesion by histamine and VEGFs leading pro-angiogenic EC phenotype, we studied this further in primary venous and aortic ECs at 4and 7-h time points after stimulation. By RNA-seq (HUVEC, $7 \mathrm{~h}$ ) both histamine and VEGF were shown to regulate expression of genes involved in $\mathrm{AJ}$ and $\mathrm{TJ}$ cell-cell adhesion modulation as well as organization of actin filaments that mediate gap formation between ECs (Fig. 3a; Suppl. Fig. 1C). By IF staining, downregulation of the major TJ protein claudin-5 (CLDN5) was evident, whereas no detectable changes in the expression of the major AJ protein VE-cadherin (CDH5) was seen in HUVECs at 7-h time point (Fig. 3b). To further confirm that VE-cadherin 

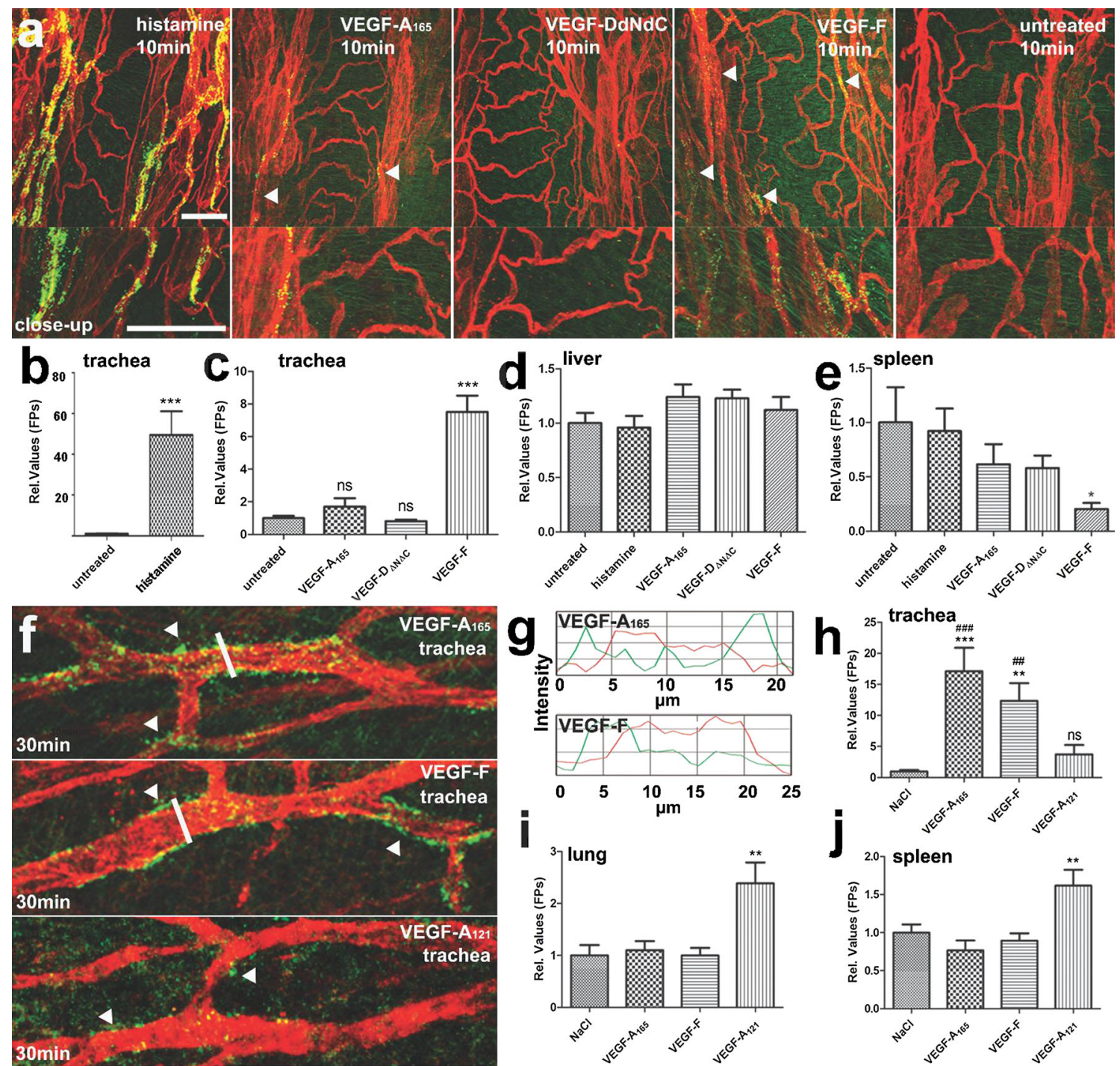

Fig. 2 Tissue-specific and time-dependent vascular hyperpermeability in intact vasculature of mice after short-term induction by histamine and VEGFs. a Tracheal whole mounts labeled with endothelium marker CD31 (red). Intravenous administration of histamine $(25 \mu \mathrm{g} / \mathrm{g})$ or VEGFs $(0.25 \mu \mathrm{g} / \mathrm{g})$ together with $200-\mathrm{nm}$ fluorescent microspheres (green) in C57/B16 mice at $10 \mathrm{~min}$ after exposure. $\mathrm{NaCl}$ was used as a negative control together with fluorescent microspheres (untreated). Scale bar, $100 \mu \mathrm{m}$. b-e Quantification of the vascular leakage from trachea $(\mathbf{b}, \mathbf{c})$, liver $(\mathbf{d})$ and

expression levels were not changed in stimulated ECs, qRTPCR was performed, showing that only a slight increase was detected in VE-cadherin mRNA levels after $7 \mathrm{~h}$ of exposure by VEGF-A ${ }_{165}$, VEGF-F and histamine (Suppl. Fig. 1E). Consistently with the results at 30-min time point, re-organization of VE-cadherin on the cell surface of histamine- or VEGF-stimulated ECs was visible at 7-h time point (Fig. 3b). Next, we validated CLDN5 expression by qRT-PCR experiments. The results further confirmed the significant downregulation of CLDN5 in both venous (HUVEC; 4, $7 \mathrm{~h}$ ) and aortic (HAEC; $7 \mathrm{~h}$ ) primary ECs after

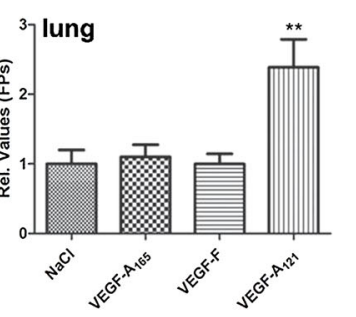

spleen (e) at $10 \mathrm{~min}$ after exposure. f, $\mathbf{g}$ Close-up and plot profile views of the $20-\mu \mathrm{m}$-sized leaky vessels are presented after $30 \mathrm{~min}$ of exposure to VEGFs, showing fluorescent microspheres (green line) outside of the vessels (red line, $\mathbf{f}$ ). White bars represent the site from which the corresponding intensity plot profile area is derived $(\mathbf{g})$. hj Quantification of vascular leakage from trachea (h), lung (i) and spleen (j) at 30 min after VEGF exposure. In all data, mean \pm SEM presented $\left(n=4-5\right.$ mice/group). $P$ values $<0.05^{*} ;<0.01^{* *}$; $<0.001 * * *$

exposure by VEGF-A $\mathrm{A}_{121}$, VEGF- $\mathrm{A}_{165}$, VEGF-F and histamine, whereas VEGF- $\mathrm{D}_{\Delta \mathrm{N} \Delta \mathrm{C}}$ had no effect (Fig. 3c; Suppl. Fig. 1F). Being in line with in vitro data, a trend in CLDN5 downregulation was detected in lung tissue of C57/ Bl6 mice after $4 \mathrm{~h}$ of exposure (i.v.) to VEGF- $\mathrm{A}_{165}$, VEGF$\mathrm{F}$ or histamine, albeit the effect was not statistically significant (Suppl. Fig. 1H). These data implicated that high affinity binding of VEGF to VEGFR2 regulates CLDN5 expression and thereby EC-EC adhesion.

To further address the question, whether histamineand VEGF-induced CLDN5 downregulation was specific 

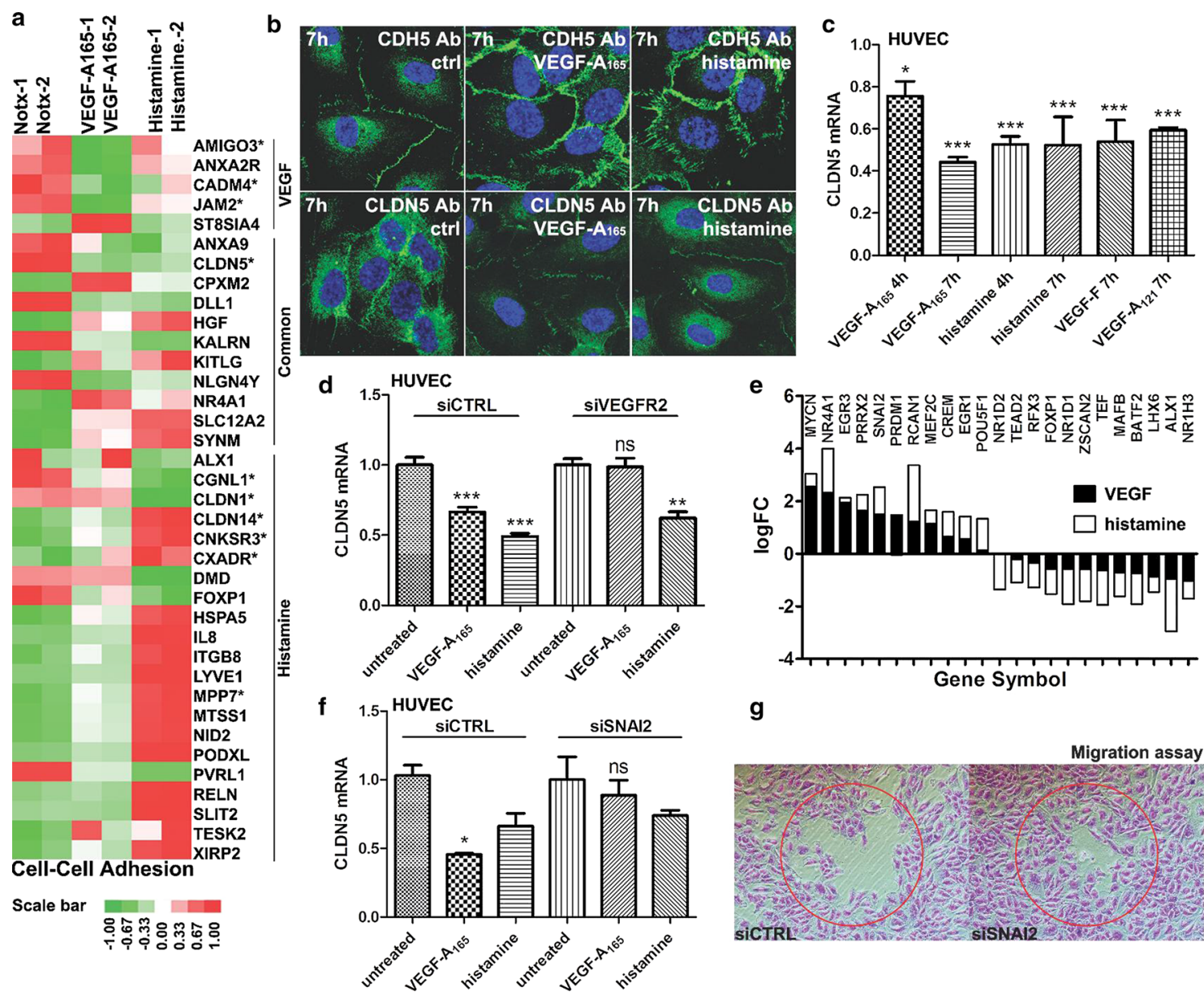

g
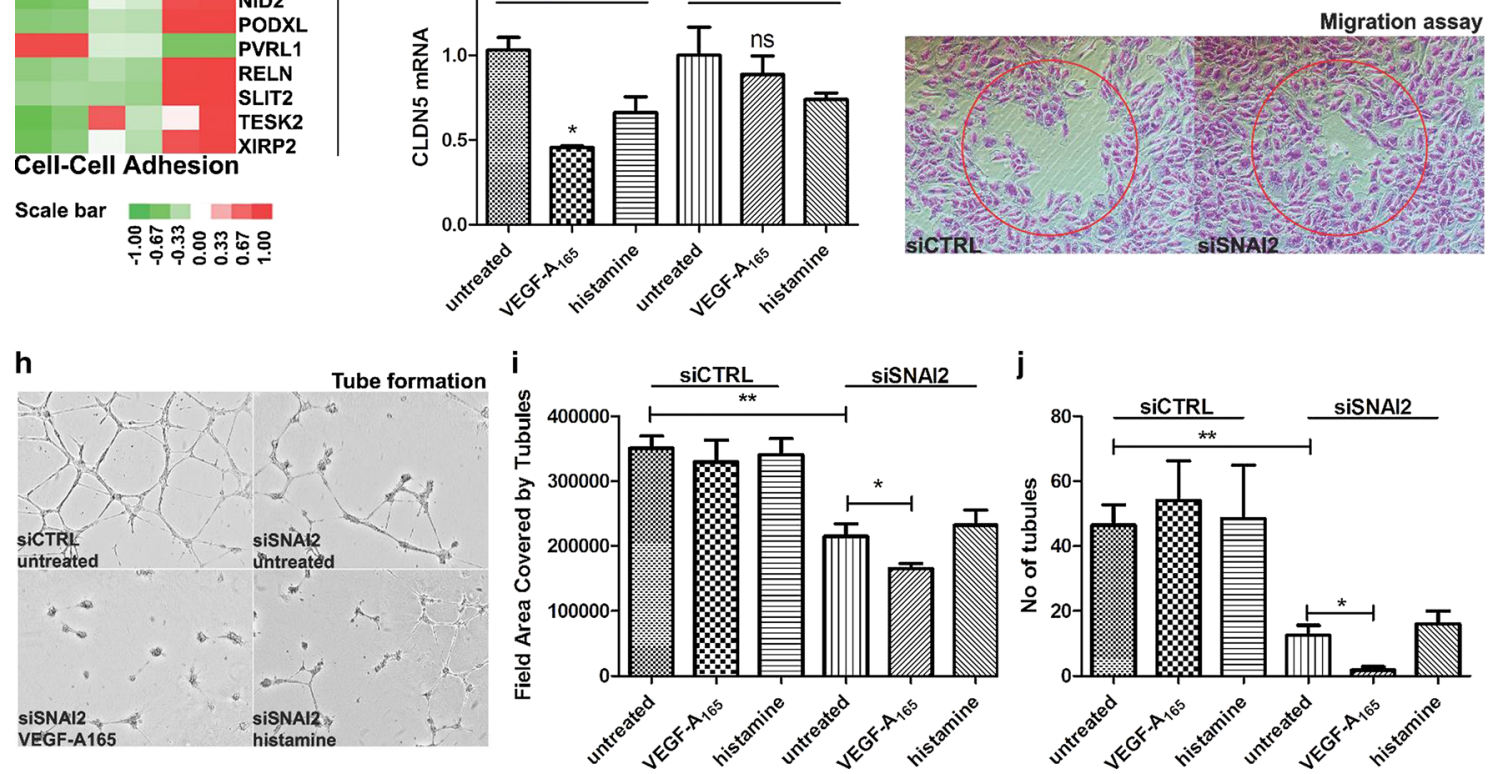

Fig. 3 Regulation of cell-cell adhesion by histamine and VEGFs in ECs. a Heat map showing genes in cell-cell adhesion after VEGF and histamine stimulation for $7 \mathrm{~h}$ in HUVEC cells by RNA-seq. Normalized gene expression values are shown (red, upregulated; green, downregulated genes). In all data, two independent experiments from separate donors were performed ( $n=4$ donors). b VE-cadherin (CDH5 Ab, upper panel, green) and claudin-5 (CLDN5 Ab, lower panel, green) immunofluorescent staining of HUVECs after VEGF treatment for $7 \mathrm{~h}$ showed claudin-5 downregulation induced by both VEGF and histamine. No changes were detected in VE-cadherin expression. DAPI (blue) was used for staining nuclei. $\mathbf{c}$ mRNA expression levels of CLDN5 after 4- and 7-h stimulation with histamine or VEGFs in HUVECs detected by qRT-PCR. d CLDN5 mRNA expression levels in VEGFR2 (siVEGFR2) or control (siCTRL) siRNA-silenced HUVECs after 7-h stimulation with histamine or VEGF-A detected by qRT-PCR. e Genes involved in the regulation of transcriptional activity by VEGF and histamine. Log fold changes are shown. In all data, two independent experiments from separate donors were performed ( $n=4$ donors). f CLDN5 mRNA expression levels in zinc finger protein SNAI2 (siSNAI2) or control (siCTRL) siRNA-silenced HUVECs after 7-h stimulation with histamine or VEGF-A detected by qRT-PCR. g Migration assay in HUVECs after 48-h siRNA treatment with siSNAI2 and siCTRL. Cell staining was performed in order to visualize EC migration according to manufacturer's instructions ( 3 independent experiments; $n=3$ wells/siRNA) and visualized with brightfield microscopy. Magnification $20 \times$. H-j In vitro tube formation assay in HUVECs after 48-h siRNA treatment with siSNAI2 and siCTRL and 7-h stimulation with histamine or VEGF (h). Field area (i) and number of tubules (j) are shown. Quantitation of tubules was performed by Angiosys program. In all data, mean \pm SEM presented. $P$ values $<0.05^{*} ;<0.01^{* *} ;<0.001^{* * *}$. All experiments were performed with VEGF concentration of $100 \mathrm{ng} / \mathrm{ml}$ and with $20 \mu \mathrm{M}$ histamine. In all experiments, 3 independent experiments were performed ( 3 replicates/experiment, HUVEC $<p 5$ ) 
to their vascular permeability-inducing receptors H1R and VEGFR2, siRNA experiments against VEGFR2 and H1R inhibitor experiments were performed. In siVEGFR2treated ECs, histamine but not VEGF was able to downregulate CLDN5 expression (Fig. 3d). Similarly, histamine receptor inhibitor was able to block histaminemediated CLDN5 downregulation but had no effect on VEGF (Suppl Fig. 1g). Therefore, these data demonstrate that CLDN5 is regulated independently by both histamine and VEGF. Interestingly, RNA-seq data showed that in addition to downregulation of CLDN5 by both VEGF and histamine, both factors regulated several other junctional molecules independently. VEGF was shown to downregulate cell-cell adhesion genes such as immunoglobulin superfamily cell adhesion receptors (AMIGO3, CADM4) and junction adhesion molecule 2 (JAM2). Histamine instead regulated other genes associated with TJs, e.g., claudin superfamily members (CLDN1, CLDN14), Coxsackie virus and adenovirus receptor (CXADR), cingulinlike 1 (CGNL1), membrane-associated guanylate kinase CNKSR3 and membrane protein MPP7 (Fig. 3a). These data suggest that regulation of EC adhesion is a complex process, in which multiple genes play a role simultaneously. CLDN5 was shown to be the main adhesion gene regulated by both histamine and VEGF. We also demonstrated that high affinity binding of VEGFs to VEGFR2 and histamine binding to H1R regulate CLDN5 expression. To conclude, although it has been shown that internalization of VE-cadherin due to well-known phosphorylation cascades is an important factor in induction of EC permeability after short-term stimulation by histamine and VEGF, CLDN5 is also regulated at the expression level in both venous and aortic ECs. Interestingly, prior to our study, CLDN5 expression has been demonstrated to affect EC cell motility and matrix adhesion [14, 15].

\section{VEGF regulates gene expression of claudin-5 via a transcription factor SNAI2}

Transcription factors (TFs) are crucial in regulating angiogenic processes. Therefore, we studied further the role of pro-angiogenic TFs regulating CLDN5 expression in histamine- and VEGF-stimulated ECs. Previously several studies have shown regulation of CLDN5 by transcription factors such as FoxO1, ERG and RUNX1 [16-18]. However, common histamine- and VEGF-induced CLDN5 upstream regulators have not been previously presented and the separate studies have usually focused only on one TF $[17,18]$. In our omics approach, we detected by RNA-seq multiple TFs regulated by both histamine and VEGF, such as NR4A1, RCAN1 and MAFB (7 h, HUVEC). Additionally, 13 other TFs were specifically regulated by histamine and 8 TFs by VEGF such as
SNAI2 (Fig. 3e). Since SNAI2 has been previously suggested to act as a transcriptional regulator of claudin-1 in keratinocytes [19] and to enhance cancer cell migration, this TF was studied first. In VEGF-treated ECs, SNAI2 expression was shown to be upregulated by 2.8 -fold $(P<0.01)$, while transcript levels were unchanged in histamine-treated HUVECs. To distinguish the role of SNAI2 and VEGFR2 signaling in potentially regulating CLDN5 expression and angiogenic processes in ECs, we next performed siRNA experiments against SNAI2 and detected the mRNA levels of CLDN5 by qRT-PCR. In addition, functional effects of SNAI2 to EC survival, tube formation, proliferation and migration were followed. First, silencing of SNAI2 (Suppl. Fig. 2A) was shown to inhibit VEGF-mediated CLDN5 downregulation but not histamine-induced effects in HUVECs (Fig. 3f). In functional assays, EC tube formation (HUVEC, 48 h; Fig. 3h-j; Suppl. Fig. 1I), measured by field covered by the tubules as well as by number of tubules and junctions, showed significant decrease of tube formation after treatment with siSNAI2, indicating a role for SNAI2 in regulating EC sprouting. Consistently, siSNAI2 treatment was shown to regulate EC migration (48 h, Fig. 3g; Suppl. 2K) and EC survival measured by MTS assay (72 h, Fig. 4m). However, no significant effect was found on EC proliferation in comparison with control siRNAs (72 h, CyQuant assay; data not shown). IF staining of F-actin in siSNAI2-treated HUVECs further showed F-actin reorganization in confluent ECs and after EC tube formation (Suppl. Fig. 1J). Previously, F-actin has been shown to be important in migration and tube formation of ECs and to be associated with TJs. Conclusively, SNAI2 was shown to be an important mediator of VEGF signaling via regulating CLDN5 and F-actin organization and affecting EC tube formation and migration. Our data further demonstrate that SNAI2 is specific for VEGF and is not regulated by histamine.

\section{TJ formation is regulated via PI3K signaling by VEGF but is independent of HGF expression}

To further define histamine- and VEGF-regulating angiogenic factors, we next assessed the role of cytokines and other growth factors that could influence EC proliferation and adhesion. To study this, we first detected all genes in our RNA-seq data that were involved in regulation of extracellular matrix (ECM) organization, as well as cytokines and growth factors. Altogether, 18 transcripts regulating ECM remodeling were detected by RNA-seq in histamine-treated ECs (7 h, HUVEC, Fig. 4a). Histamine modulated, e.g., matrix metalloproteinases (MMP10, MMP19), crucial in angiogenesis-associated cell migration, as well as a serine protease reelin (RELN), whereas VEGF 
regulated ADAM metallopeptidase (ADAMTS10) and MMP28. Whereas only minority of ECM genes were regulated similarly between histamine and VEGF, instead 14 commonly regulated genes were shown to be commonly involved in EC proliferation, such as hepatocyte growth factor (HGF; Fig. 4b; Table 3). Since HGF has previously been shown to regulate $\mathrm{TJ}$ formation and angiogenesis via PI3K-Akt pathway $[20,21]$ and could therefore act as a common nominator to histamine- and VEGF-induced CLDN5 downregulation, this was studied further. First, WB analysis of HGF-stimulated HUVECs was performed to confirm that HGF does not induce VEGF expression that could explain the similar expression profiles of histamine and VEGF. No increase in the expression level of VEGF protein was observed (7 h, HUVEC; Suppl. Fig. 1A). Next, we performed siRNA experiment against HGF receptor MET and detected CLDN5 expression levels after histamine or VEGF stimulation. No inhibition of CLDN5 downregulation by VEGF or histamine was observed (Fig. 4c), indicating that HGF does not act as a regulator of CLDN5. Consistent with previous data [20, 21], upregulation of HGF was inhibited in PI3K inhibitor-treated ECs (7 h; Fig. 4d). Conclusively, although PI3K-Akt pathway was shown to be required for VEGF- and histamine-induced HGF mRNA upregulation, HGF is not the common mediator required for regulating CLDN5 expression and subsequent TJ formation.

Our results with PI3K inhibitor (Fig. 4e) showed that PI3K-signaling was required particularly for VEGF-induced CLDN5 downregulation, whereas no effect was observed with histamine. This implied that another mechanism for histamine-induced effects existed, such as signaling via interleukin-8 (IL-8; Fig. 4b). In previous studies, IL-8 has been shown to downregulate CLDN5 expression in ECs and to induce vascular permeability [22]. In our study, IL-8 was upregulated by histamine but not by VEGF detected by qRT-PCR (HUVEC, $7 \mathrm{~h}$; Fig. 4f). To observe whether PI3K-signaling was involved in IL-8 expression, we performed qRT-PCR experiments with PI3K inhibitor-treated ECs. The data showed that inhibition of PI3K-signaling did not affect histamine-induced IL-8 upregulation (HUVEC, 7 h, Fig. 4f) or CLDN5 downregulation (Fig. 4d). These data indicated that IL8 could act as an indirect mediator of CLDN5 expression in histamine-stimulated ECs. Consistently, in siRNA experiments against IL-8, VEGF but not histamine was able to downregulate CLDN5 expression (Fig. 4g). To conclude, we show evidence that histamine and VEGF regulate $\mathrm{TJ}$ formation via complex and partially different cellular mechanisms, requiring IL8- and PI3K-Akt-dependent and independent pathways. Additionally, both factors induced upregulation of HGF; however, this
Fig. 4 Regulation of EC proliferation by histamine and VEGFs. a Heat map showing genes involved in cell-ECM adhesion regulated by VEGF and histamine ( $7 \mathrm{~h}$ ) in HUVECs by RNA-seq. Normalized gene expression values are shown (red, upregulated; green, downregulated). b Genes involved in the regulation of growth factors and cytokines by VEGF and histamine. Log fold changes are shown. In all data, two independent experiments from separate donors were performed ( $n=4$ donors). c HGF signaling does not regulate CLDN5. CLDN5 mRNA expression levels in siMET or siCTRL siRNA-treated HUVECs after stimulation with histamine or VEGF-A (7 h). d PI3K-Akt pathway is required for HGF upregulation. HGF expression in untreated and PI3K inhibitor-treated HUVECs after histamine and VEGF stimulation for $7 \mathrm{~h}$ detected by qRT-PCR. e PI3K-Akt pathway is required for CLDN5 downregulation by VEGF. CLDN5 expression in untreated and PI3K inhibitor-treated HUVECs after histamine and VEGF stimulation detected by qRTPCR. f IL- 8 is upregulated by histamine but not by VEGF. Inhibition of PI3K-signaling was not able to inhibit histamine-induced IL-8 upregulation. IL8 expression in untreated and PI3K inhibitor-treated HUVECs after 7-h VEGF and histamine stimulation is shown detected by qRT-PCR. g CLDN5 mRNA expression levels in silL8-treated HUVECs after histamine and VEGF stimulation for $7 \mathrm{~h}$ detected by qRT-PCR. $\mathbf{h}$ Upregulation of transcription factors NR4A1 and MYCN in HUVECs after histamine and VEGF stimulation (7 h). i Upregulation of NR4A1 mRNA expression and downregulation of MYCN in lung tissue by histamine and VEGFs after $4 \mathrm{~h}$ of systemic delivery detected by qRT-PCR ( $n=3-4$ mice/group). j NR4A1 regulates TJ formation. CLDN5 expression in siNR4A1, siMYCN or siCTRL siRNA-treated HUVECs after 7-h stimulation with histamine or VEGF detected by qRT-PCR. $\mathbf{k}$ MYCN protein expression is upregulated by VEGFs, but not by histamine in HUVECs after $7 \mathrm{~h}$ of treatment detected by WB. I In vitro tube formation assay in HUVECs after 48-h siRNA treatment with siMYCN and 7-h stimulation with VEGF. Representative images are shown. m EC survival was decreased by siRNAs against MYCN, NR4A1 and SNAI2 detected by MTS assay $(48 \mathrm{~h})$. In all data, mean \pm SEM presented. $P$ values $<0.05^{*} ;<0.01 * * ;<0.001 * * *$. All experiments were performed with VEGF concentration of $100 \mathrm{ng} / \mathrm{ml}$ and with $20 \mu \mathrm{M}$ histamine. In all cell experiments, 3 independent experiments were performed (3 replicates/experiment, HUVEC $<p 5$ )

growth factor did not have an effect on CLDN5 expression.

\section{VEGF and histamine both regulate expression of pro-angiogenic transcription factors NR4A1 and MYCN that mediate CLDN5 expression and angiogenic processes in ECs}

To obtain understanding whether common CLDN5 upstream regulators existed by histamine and VEGF, we next studied various TFs found from RNA-seq data by siRNA experiments and functional assays in ECs. Of all the TFs, RCAN1 (regulator of calcineurin 1), NR4A1 (nuclear receptor subfamily 4 group A member 1$)$ and MYCN (Nmyc proto-oncogene protein) were the most highly upregulated TFs by histamine and/or VEGF and were thus chosen for further studies (Fig. 3e; Tables 1, 2). Besides 7-h time point used in RNA-seq, all of the studied TFs were 

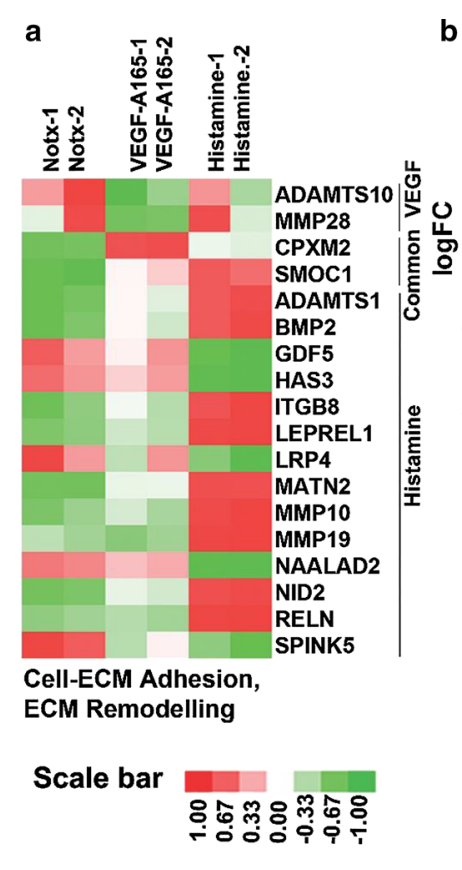

b
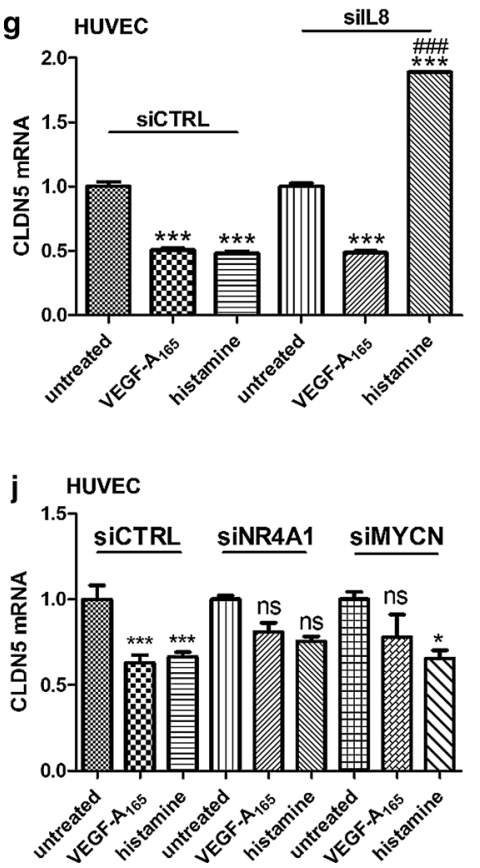

c d
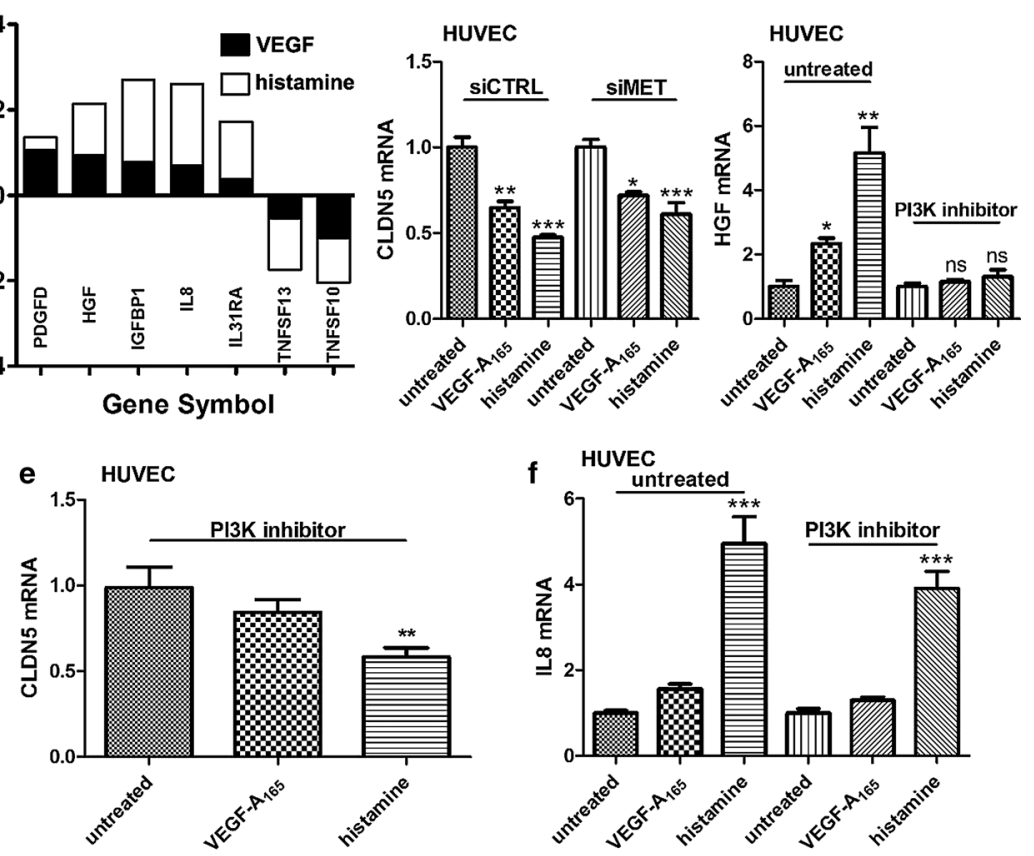

h HUVEC

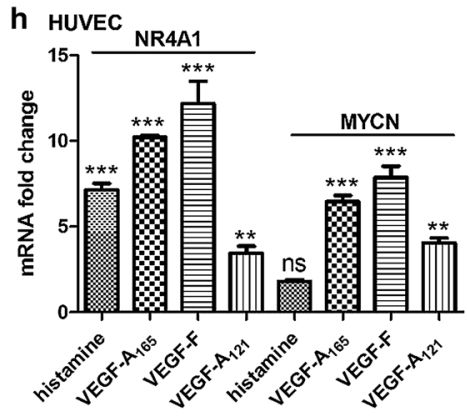

$f \quad$ HUVEC

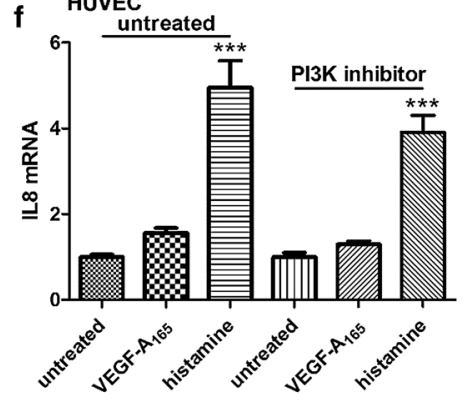

i
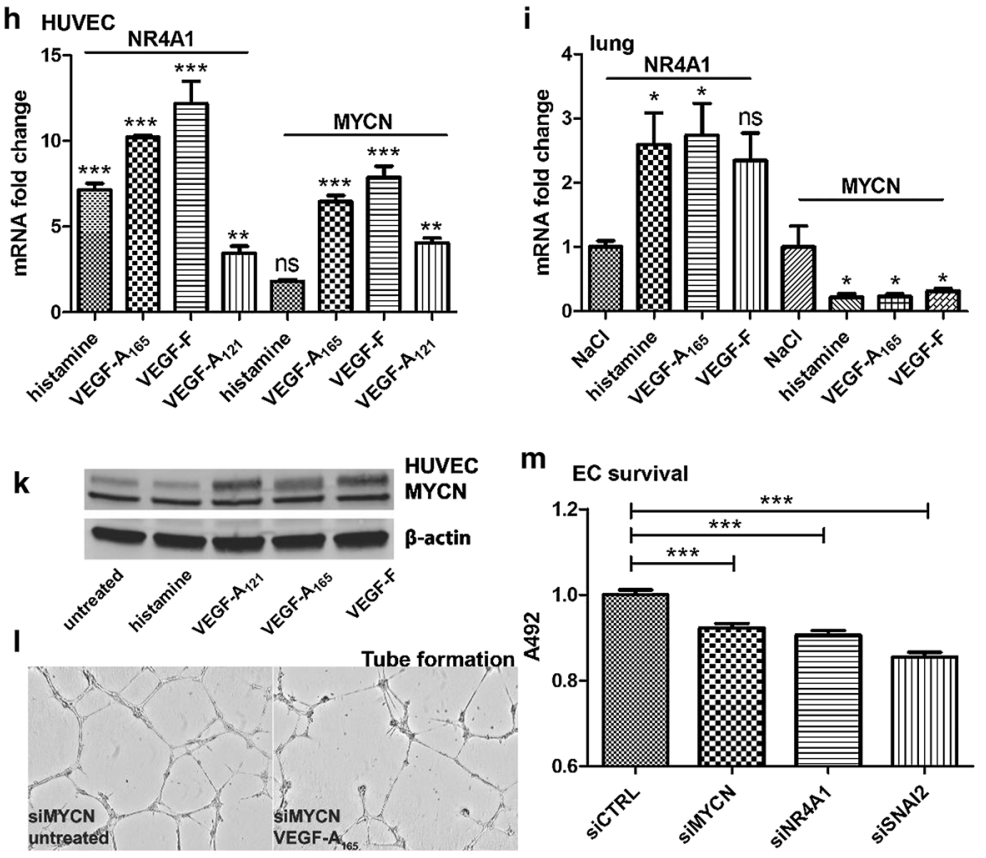

shown to be upregulated at $4 \mathrm{~h}$ by qRT-PCR (Fig. 4i; Suppl. Fig. 2C).

First RCAN1 was studied that has been previously linked with overload of calcium in ECs and vascular permeability [23]. In line with previous studies showing histamine- and VEGF-induced calcium influx [24], we observed multiple genes known to be involved in calcium uptake that were regulated commonly by both histamine and VEGF (Suppl. Fig. 2B). qRT-PCR data confirmed that RCAN1 was upregulated after stimulation with various
VEGFR2-binding VEGFs and by histamine at both 4- and 7-h time points (Suppl. Fig. 2C). To further distinguish the role of VEGFR2 in RCAN1 expression, siRNA experiments were performed against VEGFR2. The data showed that histamine but not VEGF upregulated RCAN1 expression (Suppl. Fig. 2D), thus indicating that both factors mediate RCAN1 expression independently regardless of their distinct receptor binding profiles. Besides RCAN1, both histamine and VEGF commonly regulated several other calcium-activated genes, e.g., plasma membrane 
calcium-transporting ATPase 1 (ATP2B1; Suppl. Fig. 2b, E), sodium/chloride transporter SLC12A2 and stanniocalcin-1 (STC1; Suppl. Fig. 2B, F). Interestingly, no significant changes were found in the expression levels of RCAN1, STC1, ATP2B1 or SLC12A2 by VEGF-A 121 (Suppl. Fig. 2C, E, F), whereas VEGF-F, a selective ligand of VEGFR2, induced a similar expression pattern of calcium-induced genes as VEGF- $\mathrm{A}_{165}$. These data indicated that expression of calcium-activated genes was linked to HSPG/NRP co-receptor binding of VEGFs. Finally, to detect the potential role of RCAN1 in angiogenic processes, a migration assay was performed in siRNA-treated ECs against RCAN1. The data showed no effect on EC migration in comparison with control siRNA ( $48 \mathrm{~h}$, Suppl. Fig. 2J). Therefore, we focused our study to other histamine- and VEGF-regulated TFs MYCN and NR4A1 that could potentially regulate EC adhesion and angiogenic processes.

High upregulation of NR4A1 expression, an orphan nuclear superfamily member, has been previously shown to be involved in angiogenesis and inflammation $[6,25]$. Consistently, in our study NR4A1 was upregulated in HUVECs at 4-h and 7-h time points by both histamine and VEGF (Fig. 4i; Suppl. Fig. 2G). Upregulation of NR4A1 was also detected in the lung tissue of C57/B16 mice after systemic delivery (i.v.) of both histamine, VEGF- $\mathrm{A}_{165}$ and VEGF-F after $4 \mathrm{~h}$ of exposure (Fig. $4 \mathrm{i}$ ). In comparison, MYCN gene expression, linked with regulation of cell proliferation, e.g., in neuroblastoma [26], was upregulated in ECs by all studied VEGFs at 4- and 7-h time points detected by RNA-seq, qRT-PCR and WB but only at 4-h time point with histamine (Fig. 4h, k; Suppl. Fig. 2G). A different role of MYCN in ECs compared to lung tissue was seen after systemic delivery of VEGF$\mathrm{A}_{165}$, VEGF-F or histamine in C57/B16 mice, as MYCN was shown to be downregulated (i.v., 4 h; Fig. 4 h). The importance of NR4A1 and MYCN in EC function was further analyzed in a cell survival, proliferation, migration and tube formation assays in HUVECs. The data demonstrated a significant decrease in EC survival after siRNA treatment against NR4A1 or MYCN (72 h, MTS assay; Fig. 4m; Suppl. Fig. 2A); however, no significant increase in cell proliferation (72 h, CyQuant assay, data not shown) or significant effect on EC tube formation was observed with either NR4A1 or MYCN (48 h, Fig. 41; Suppl. Fig. 2H). In migration assay instead, siNR4A1 increased EC migration (48 h, Suppl. Fig. 2J, K), showing that these factors are important regulators of EC adhesion. Next, to address the question whether MYCN or NR4A1 regulates CLDN5 expression and thereby affects EC adhesion/migration, qRT-PCR experiments were performed in siRNA-treated ECs. Treatment of ECs with siRNA against MYCN was shown to inhibit only
VEGF-induced CLDN5 downregulation, whereas no effect was observed with histamine (HUVEC, $7 \mathrm{~h}$; Fig. 4i). Instead either histamine or VEGF was not able to downregulate expression of CLDN5 in siNR4A1-treated ECs (HUVEC, Fig. 4j). Consistently, in ECs treated with siCLDN5 histamine and VEGF were still able to upregulate NR4A1 (data not shown). Thus, these data demonstrated that NR4A1 acts as an upstream regulator of CLDN5. Finally, to further study the role of VEGFR2 in inducing NR4A1 upregulation, experiment with siRNA against VEGFR2 was performed. The data showed that upregulation of NR4A1 was independent on VEGFR2 expression (Suppl. Fig. 2I). Conclusively, these data indicate that an indirect mechanism, independent of VEGFR2 signaling, induces upregulation of NR4A1 after stimulation by histamine and VEGF and downregulates CLDN5 expression. Interestingly, NR4A1 has been previously shown to be upregulated by inflammation mediators TNF-alpha and interleukin-1 $\beta$ [27].

Altogether, these data demonstrate that both edematogenic factors VEGF and histamine regulate multiple genes

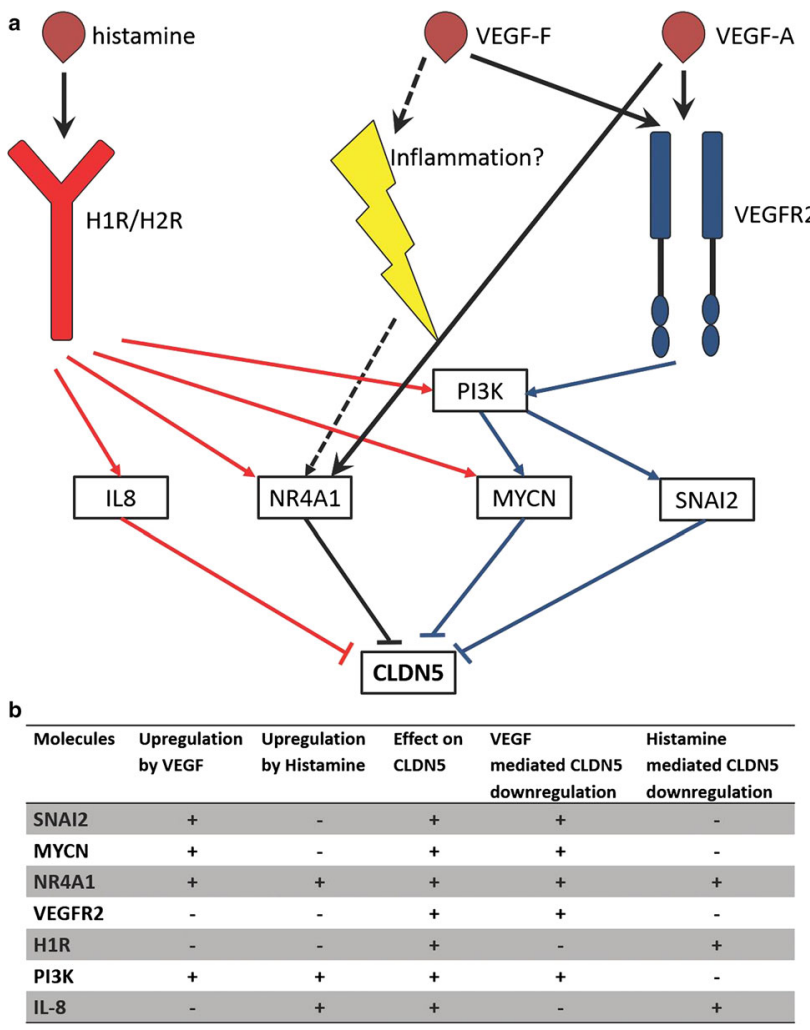

Fig. 5 Claudin-5 downregulation by histamine and VEGF in ECs. a Histamine and VEGF-A commonly downregulated CLDN5 via NR4A1. VEGF-A induced VEGFR2-mediated CLDN5 downregulation via PI3K pathway (blue lines), whereas histamine-induced CLDN5 downregulation via IL-8 (red lines). We hypothesize that snake venom-derived VEGF-F induces NR4A1 expression due to inflammation signaling. b CLDN5 as a molecular target of VEGF or histamine. Molecules found to be involved in this study are shown 
involved in EC adhesion, calcium signaling and EC migration that induce the development of pro-angiogenic EC phenotype (Fig. 5). Regulation of CLDN5 expression by VEGF and histamine involves PI3K signaling and previously unknown CLDN5 upstream regulators SNAI2, NR4A1 and MYCN. Prior to this study, these factors and RCAN1 have not been linked to histamine. Additionally, histamine was shown to regulate angiogenic cellular processes independently of VEGFR2.

\section{Discussion}

Physiological effects of VEGFs and histamine on the vasculature are well established, but postreceptor signaling pathways and gene regulation affecting angiogenesis are not fully understood. Using RNA-seq and functional assays, we compared gene regulation by VEGF and histamine in primary ECs and in the vasculature of C57/B16 mice after systemic delivery. Altogether, 76 commonly regulated genes were found between histamine- and VEGF-stimulated ECs by RNA-seq, representing 53\% of all VEGF-regulated transcripts and $\sim 26 \%$ of all histamine-regulated transcripts. Several of the genes encoded proteins important for cell junction stability, cytoskeleton organization and cell-ECM adhesion thereby affecting EC integrity and proliferation. Particularly, VEGF induced changes in the immunoglobulin superfamily cell adhesion receptors and genes involved in the stabilizing/regulating TJs and AJs, whereas histamine regulated mainly transcripts linked to TJ function. Both histamine and VEGF reduced expression of the major TJ protein claudin-5 that has previously been connected to pathological angiogenesis, increased macromolecule influx [28] and blood-brain barrier breakdown [29]. Although changes in VE-cadherin and F-actin organization were found after both short- $(4 \mathrm{~h})$ and long-term stimulation (7 h), no major changes in gene expression level of VE-cadherin were detected with either histamine or VEGF in our study. This indicates that claudin-5 may be more regulated at the transcriptional level, whereas VE-cadherin is mainly regulated at the posttranslational level [13]. Changes in claudin-5 expression have been previously connected to pathological angiogenesis, e.g., in cancer [30]. In addition to claudin-5, histamine upregulated several cell adhesion molecules that is a known hallmark of inflammation and H1R-mediated signaling.

Decreased cell-cell adhesion has been reported to promote angiogenesis and is likely regulated by multiple factors at the gene expression level. Also claudin-5 has been connected to regulation of EC motility and matrix adhesion [14, 15]. Previously, histamine has been suggested to promote vessel growth in tumors, as well as to induce EC proliferation and angiogenesis by upregulating expression of VEGF or the pro-angiogenic transcription factor NR4A1 [6, 31]. In our study, no upregulation of VEGFs/VEGFRs was detected after histamine stimulation. Additionally, inhibition experiments by VEGFR2 siRNA did not reduce histamine-mediated regulation of specific genes (e.g., RCAN1, CLDN5 and NR4A1). Therefore, our results are in line with the previous finding of Qin et al. [6] that histamine is able to induce VEGFR2-independent angiogenic signaling. Moreover, we also show that the cellular mechanisms required to induce angiogenic processes by histamine are more complex than earlier reported direct regulation via NR4A1 and instead involve changes in the expression levels of multiple genes, including growth factors, cytokines, transcription factors and calcium-dependent cell signaling events. Altogether, 14 commonly regulated genes were directly involved in cell proliferation by histamine and VEGF. A common mediator of EC proliferation was shown to be HGF, which has previously been linked to induce EC proliferation via PI3K-Akt pathway [20], and to be upregulated after ischemic injury [21] and in cancer [20]. HGF, however, had no effect on claudin-5 expression in our study. To identify the transcription factors required for cell adhesion/proliferation by histamine and VEGF, functional studies were further performed based on RNA-seq data. SNAI2 was shown to be exclusively regulated by VEGF, whereas NR4A1, MYCN and RCAN1 were regulated by both factors. Of these factors SNAI2, NR4A1 and MYCN were shown to act as upstream regulators of CLDN5 and to be important factors in EC migration. MYCN expression has been previously linked to integrin-mediated cell adhesion and PI3K-mediated VEGF regulation in neuroblastoma [26]. SNAI2 has been shown to repress claudin-1 expression in keratinocytes [19] and to be upregulated in pathological angiogenesis. RCAN1 has been connected to VEGF signaling and regulation of angiogenesis via NFAT signaling [32]. Importantly, prior to this study, histamine signaling has not been connected to these genes. Furthermore, we demonstrate that NR4A1, MYCN and SNAI2 induce downregulation of claudin-5 and are required for EC migration. Since both NR4A1 and RCAN1 have been shown to be upregulated after elevated intracellular calcium levels [23, 33] and changes in gene expression of calcium transporters were detected with both histamine and VEGF, this together with HGF-induced signaling may explain the observed similar gene expression patterns found between the factors. We also demonstrate that interleukin- 8 regulates claudin- 5 expression by histamine via PI3K-independent pathway. This is in agreement with a previous study, showing that interleukin- 8 induces EC permeability and angiogenesis by downregulating claudin-5 [22]. Overall, although the role of calcium in mediating angiogenesis needs further clarification, 
calcium overload seems to lead to upregulation of multiple TFs [34] that promote angiogenic processes in ECs by histamine and VEGF. Besides our data, other TFs such as FoxO1, Erg and Runx1 have been connected to regulate claudin- 5 after stimulation of ECs by Vegf, interleukin- $1 \beta$ or thrombin [16-18, 35, 36]; however, changes in the expression levels by these factors were not observed in our study. This may indicate to cell-type-specific differences, e.g., in aortic and venous ECs. These cell-type-specific differences may also exist between histamine- and VEGFinduced functional effects.

As VEGFs have been used to induce arteriogenesis and angiogenesis to treat coronary and peripheral vascular diseases, understanding their potential adverse effects is of great importance for future clinical use. Our group previously demonstrated that VEGF therapy in preclinical animal models successfully induced blood vessel growth, increased skeletal muscle perfusion but simultaneously caused edema [37]. So far the mechanisms regulating cellcell adhesion and EC permeability have been poorly understood, although numerous genes have been linked with vascular permeability [38]. We show here that systemic delivery of histamine and VEGF-F causes vascular hyperpermeability of $200-\mathrm{nm}$-sized particles $(<10 \mathrm{~min})$ in the intact vasculature of mice, whereas VEGF- $\mathrm{A}_{165}$ induces a slower hyperpermeability response $(<30 \mathrm{~min})$. Previously, the majority of vascular permeability studies have been performed locally in skin by using the modified Miles assay. However, the Miles assay, although effective, has been shown to induce inflammation at site or in individually perfused vessels [39]. Based on these methods, VEGF$\mathrm{F}$ has been suggested as a more potent vasodilator than VEGF-A $_{165}$ [40], whereas VEGF- $A_{121}$ and VEGF-A 165 induce similar local responses [11]. Our data, however, show that VEGF-induced vascular hyperpermeability after systemic delivery (1) varies among different vascular beds and (2) is time dependent. Both VEGF-A 165 and VEGF-F cause similar responses over time. Time-dependent variation of VEGFs is likely explained by VEGF- $\mathrm{A}_{165}$ binding to VEGFR1/VEGFR2, whereas VEGF-F only binds to VEGFR2. To our knowledge, this is the first comprehensive study evaluating VEGF-induced effects on vascular permeability in intact vasculature of mice in various vascular beds. Additionally, in our EC permeability model, VEGF-A $_{121}$ was not able to induce EC permeability or induce changes in VE-cadherin localization or F-actin organization. Additional differences were detected in the expression levels of calcium-induced genes (e.g., ATP2B1, SLC12A2, STC1) by VEGF-A $A_{121}$ and other VEGFR2binding VEGFs. The obtained knowledge is valuable for safety evaluation of VEGFs for pro-angiogenic therapy.

Previously, EC function has been suggested to require regulation not only at transient phosphorylation level but also at transcriptional level [41]. In this study, we identified novel common molecular players influencing EC activation, migration and adhesion by VEGFs and histamine. Our results on the regulation of vascular endothelium improve general understanding of pathological angiogenesis and may provide novel treatment targets, such as RCAN1, MYCN and SNAI2 for treatment of vascular pathologies. Regulation of, e.g., MYCN signaling by CDK7 inhibitors [42] or NR4A1 signaling by calcineurin inhibitors [43] may also be beneficial in pro-angiogenic therapy to reduce edema.

Acknowledgements This study was supported by Academy of Finland (Project No. 250614), CoE of Cardiovascular and Metabolic Disease, ERC Advanced Grant (AdG09-250050) and CARIM PhD and VENI fellowships of the Netherlands Organization of Scientific Research (016.116.017). The personnel of the Kuopio University Hospital maternity ward are thanked for providing the umbilical cords for HUVEC cell isolation.

Author contributions JPL (Laakkonen) designed, performed research, wrote the paper and provided materials and reagents for the study. JPL (Lappalainen) performed research and wrote the paper. TLT performed research, optimized 2-photon microscopy experiments and edited the paper. PIT and TN contributed VEGF proteins to the study. SJ performed cell experiments and isolated primary human endothelial cells. MUK performed RNA sequencing and data analysis. JCS and SYH edited the paper and provided materials and reagents for the study.

Disclosure None.

\section{References}

1. Kumar P, Shen Q, Pivetti CD, Lee ES, Wu MH, Yuan SY (2009) Molecular mechanisms of endothelial hyperpermeability: implications in inflammation. Expert Rev Mol Med 11:e19

2. Olsson AK, Dimberg A, Kreuger J, Claesson-Welsh L (2006) VEGF receptor signalling - in control of vascular function. Nat Rev Mol Cell Biol 7:359-371

3. Asai K, Kanazawa H, Kamoi H, Shiraishi S, Hirata K, Yoshikawa J (2003) Increased levels of vascular endothelial growth factor in induced sputum in asthmatic patients. Clin Exp Allergy 33:595-599

4. Brouillard P, Vikkula M (2003) Vascular malformations: localized defects in vascular morphogenesis. Clin Genet 63:340-351

5. Abdel-Majid RM, Marshall JS (2004) Prostaglandin E2 induces degranulation-independent production of vascular endothelial growth factor by human mast cells. J Immunol 172:1227-1236

6. Qin L, Zhao D, Xu J, Ren X, Terwilliger EF, Parangi S, Lawler J, Dvorak HF, Zeng H (2013) The vascular permeabilizing factors histamine and serotonin induce angiogenesis through TR3/Nur77 and subsequently truncate it through thrombospondin-1. Blood 121:2154-2164

7. Norrby K (1995) Evidence of a dual role of endogenous histamine in angiogenesis. Int $\mathrm{J}$ Exp Pathol 76:87-92

8. Zauberman H, Michaelson IC, Bergmann F, Maurice DM (1969) Stimulation of neovascularization of the cornea by biogenic amines. Exp Eye Res 8:77-83

9. Ghosh AK, Hirasawa N, Ohtsu H, Watanabe T, Ohuchi K (2002) Defective angiogenesis in the inflammatory granulation tissue in 
histidine decarboxylase-deficient mice but not in mast cell-deficient mice. J Exp Med 195:973-982

10. Wang D, Garcia-Bassets I, Benner C, Li W, Su X, Zhou Y, Qiu J, Liu W, Kaikkonen MU, Ohgi KA, Glass CK, Rosenfeld MG, Fu XD (2011) Reprogramming transcription by distinct classes of enhancers functionally defined by eRNA. Nature 474:390-394

11. Nieminen T, Toivanen PI, Rintanen N, Heikura T, Jauhiainen S, Airenne KJ, Alitalo K, Marjomaki V, Yla-Herttuala S (2014) The impact of the receptor binding profiles of the vascular endothelial growth factors on their angiogenic features. Biochim Biophys Acta 1840:454-463

12. Dejana E, Tournier-Lasserve E, Weinstein BM (2009) The control of vascular integrity by endothelial cell junctions: molecular basis and pathological implications. Dev Cell 16:209-221

13. Gavard J, Gutkind JS (2006) VEGF controls endothelial-cell permeability by promoting the beta-arrestin-dependent endocytosis of VE-cadherin. Nat Cell Biol 8:1223-1234

14. Escudero-Esparza A, Jiang WG, Martin TA (2012) Claudin-5 is involved in breast cancer cell motility through the N-WASP and ROCK signalling pathways. J Exp Clin Cancer Res 31:43-9966$31-43$

15. Escudero-Esparza A, Jiang WG, Martin TA (2012) Claudin-5 participates in the regulation of endothelial cell motility. Mol Cell Biochem 362:71-85

16. Taddei A, Giampietro C, Conti A, Orsenigo F, Breviario F, Pirazzoli V, Potente M, Daly C, Dimmeler S, Dejana E (2008) Endothelial adherens junctions control tight junctions by VEcadherin-mediated upregulation of claudin-5. Nat Cell Biol 10:923-934

17. Yuan L, Le Bras A, Sacharidou A, Itagaki K, Zhan Y, Kondo M, Carman CV, Davis GE, Aird WC, Oettgen P (2012) ETS-related gene (ERG) controls endothelial cell permeability via transcriptional regulation of the claudin 5 (CLDN5) gene. J Biol Chem 287:6582-6591

18. Miao YS, Zhao YY, Zhao LN, Wang P, Liu YH, Ma J, Xue YX (2015) MiR-18a increased the permeability of BTB via RUNX1 mediated down-regulation of ZO-1, occludin and claudin-5. Cell Signal 27:156-167

19. Martinez-Estrada OM, Culleres A, Soriano FX, Peinado H, Bolos V, Martinez FO, Reina M, Cano A, Fabre M, Vilaro S (2006) The transcription factors Slug and Snail act as repressors of Claudin-1 expression in epithelial cells. Biochem J 394:449-457

20. Naran S, Zhang X, Hughes SJ (2009) Inhibition of HGF/MET as therapy for malignancy. Expert Opin Ther Targets 13:569-581

21. Jennische E, Ekberg S, Matejka GL (1993) Expression of hepatocyte growth factor in growing and regenerating rat skeletal muscle. Am J Physiol 265:C122-C128

22. Yu H, Huang X, Ma Y, Gao M, Wang O, Gao T, Shen Y, Liu X (2013) Interleukin-8 regulates endothelial permeability by downregulation of tight junction but not dependent on integrins induced focal adhesions. Int J Biol Sci 9:966-979

23. Sobrado M, Ramirez BG, Neria F, Lizasoain I, Arbones ML, Minami T, Redondo JM, Moro MA, Cano E (2012) Regulator of calcineurin 1 (Rcan1) has a protective role in brain ischemia/ reperfusion injury. J Neuroinflammation 9:48-2094-9-48

24. Tiruppathi C, Ahmmed GU, Vogel SM, Malik AB (2006) $\mathrm{Ca}_{2}+$ signaling, TRP channels, and endothelial permeability. Microcirculation 13:693-708

25. Pei L, Castrillo A, Chen M, Hoffmann A, Tontonoz P (2005) Induction of NR4A orphan nuclear receptor expression in macrophages in response to inflammatory stimuli. J Biol Chem 280:29256-29262

26. Kang J, Rychahou PG, Ishola TA, Mourot JM, Evers BM, Chung DH (2008) N-myc is a novel regulator of PI3K-mediated VEGF expression in neuroblastoma. Oncogene 27:3999-4007
27. You B, Jiang YY, Chen S, Yan G, Sun J (2009) The orphan nuclear receptor Nur77 suppresses endothelial cell activation through induction of IkappaBalpha expression. Circ Res 104:742-749

28. Wessel F, Winderlich M, Holm M, Frye M, Rivera-Galdos R, Vockel M, Linnepe R, Ipe U, Stadtmann A, Zarbock A, Nottebaum AF, Vestweber D (2014) Leukocyte extravasation and vascular permeability are each controlled in vivo by different tyrosine residues of VE-cadherin. Nat Immunol 15:223-230

29. Argaw AT, Gurfein BT, Zhang Y, Zameer A, John GR (2009) VEGF-mediated disruption of endothelial CLN-5 promotes blood-brain barrier breakdown. Proc Natl Acad Sci USA 106:1977-1982

30. Herr D, Sallmann A, Bekes I, Konrad R, Holzheu I, Kreienberg R, Wulff C (2012) VEGF induces ascites in ovarian cancer patients via increasing peritoneal permeability by downregulation of Claudin 5. Gynecol Oncol 127:210-216

31. Zeng H, Qin L, Zhao D, Tan X, Manseau EJ, Van Hoang M, Senger DR, Brown LF, Nagy JA, Dvorak HF (2006) Orphan nuclear receptor TR3/Nur77 regulates VEGF-A-induced angiogenesis through its transcriptional activity. J Exp Med 203:719-729

32. Baggott RR, Alfranca A, Lopez-Maderuelo D, Mohamed TM, Escolano A, Oller J, Ornes BC, Kurusamy S, Rowther FB, Brown JE, Oceandy D, Cartwright EJ, Wang W, Gomez-Del Arco P, Martinez-Martinez S, Neyses L, Redondo JM, Armesilla AL (2014) Plasma Membrane calcium ATPase isoform 4 inhibits vascular endothelial growth factor-mediated angiogenesis Through interaction with calcineurin. Arterioscler Thromb Vasc Biol 34:2310-2320

33. Pinato G, Pegoraro S, Visentini M, Ruaro ME, Torre V (2009) Elevation of somatic $\mathrm{Ca}_{2}+$ upregulates genes $\mathrm{Nr} 4 \mathrm{a} 1$ and Egr2, but not Bdnf and Arc. Neuroreport 20:869-874

34. Mellstrom B, Savignac M, Gomez-Villafuertes R, Naranjo JR (2008) $\mathrm{Ca}_{2}+$-operated transcriptional networks: molecular mechanisms and in vivo models. Physiol Rev 88:421-449

35. Beard RS Jr, Haines RJ, Wu KY, Reynolds JJ, Davis SM, Elliott JE, Malinin NL, Chatterjee V, Cha BJ, Wu MH, Yuan SY (2014) Non-muscle Mlck is required for beta-catenin- and FoxO1-dependent downregulation of Cldn5 in IL-1beta-mediated barrier dysfunction in brain endothelial cells. J Cell Sci 127:1840-1853

36. Kondo N, Ogawa M, Wada H, Nishikawa S (2009) Thrombin induces rapid disassembly of claudin-5 from the tight junction of endothelial cells. Exp Cell Res 315:2879-2887

37. Rissanen TT, Korpisalo P, Markkanen JE, Liimatainen T, Orden MR, Kholova I, de Goede A, Heikura T, Grohn OH, Yla-Herttuala S (2005) Blood flow remodels growing vasculature during vascular endothelial growth factor gene therapy and determines between capillary arterialization and sprouting angiogenesis. Circulation 112:3937-3946

38. Nagy JA, Benjamin L, Zeng H, Dvorak AM, Dvorak HF (2008) Vascular permeability, vascular hyperpermeability and angiogenesis. Angiogenesis 11:109-119

39. Fu BM, Shen S (2004) Acute VEGF effect on solute permeability of mammalian microvessels in vivo. Microvasc Res 68:51-62

40. Matsunaga Y, Yamazaki Y, Suzuki H, Morita T (2009) VEGF-A and VEGF-F evoke distinct changes in vascular ultrastructure. Biochem Biophys Res Commun 379:872-875

41. Goddard LM, Iruela-Arispe ML (2013) Cellular and molecular regulation of vascular permeability. Thromb Haemost 109:407-415

42. Chipumuro E, Marco E, Christensen CL, Kwiatkowski N, Zhang T, Hatheway CM, Abraham BJ, Sharma B, Yeung C, Altabef A, Perez-Atayde A, Wong KK, Yuan GC, Gray NS, Young RA, George RE (2014) CDK7 inhibition suppresses super-enhancer- 
linked oncogenic transcription in $\mathrm{MYCN}$-driven cancer. Cell 159:1126-1139

43. Wang X, Hayashi S, Umezaki M, Yamamoto T, Kageyama-Yahara N, Kondo T, Kadowaki M (2014) Shikonin, a constituent of
Lithospermum erythrorhizon exhibits anti-allergic effects by suppressing orphan nuclear receptor $\mathrm{Nr} 4 \mathrm{a}$ family gene expression as a new prototype of calcineurin inhibitors in mast cells. Chem Biol Interact 224C:117-127 